\title{
Gabriel De Llobet, Mgr de Llobet. Un pasteur intransigeant face aux défis de son temps (1872-1957)
}

Notes bibliographiques, illustrations hors-texte, index, Limoges Presses universitaires de Limoges, Cahiers de l'Institut d'Anthropologie juridique, 32, 2012, $260 \mathrm{p}$.

\section{Paul Airiau}

\section{(2) OpenEdition} Journals

Édition électronique

URL : http://journals.openedition.org/assr/25540

DOI : 10.4000/assr.25540

ISSN : $1777-5825$

Éditeur

Éditions de l'EHESS

Édition imprimée

Date de publication : 30 décembre 2013

Pagination : 232

ISSN : 0335-5985

Référence électronique

Paul Airiau, «Gabriel De Llobet, Mgr de Llobet. Un pasteur intransigeant face aux défis de son temps (1872-1957) », Archives de sciences sociales des religions [En ligne], 164 | 2013, mis en ligne le 06 mars 2014, consulté le 21 septembre 2020. URL : http://journals.openedition.org/assr/25540 ; DOI : https:// doi.org/10.4000/assr.25540

Ce document a été généré automatiquement le 21 septembre 2020.

(c) Archives de sciences sociales des religions 


\section{Gabriel De Llobet, Mgr de Llobet. Un pasteur intransigeant face aux défis de son temps (1872-1957)}

Notes bibliographiques, illustrations hors-texte, index, Limoges Presses universitaires de Limoges, Cahiers de l'Institut d'Anthropologie juridique, 32, 2012, $260 \mathrm{p}$.

Paul Airiau

\section{RÉFÉRENCE}

Gabriel De Llobet, Mgr de Llobet. Un pasteur intransigeant face aux défis de son temps (1872-1957) , Notes bibliographiques, illustrations hors-texte, index, Limoges, Presses universitaires de Limoges, Cahiers de l'Institut d'Anthropologie juridique, 32, 2012, $260 \mathrm{p}$. 
1 En 2003, Gabriel de Llobet avait publié et annoté un ensemble de documents sur la Première Guerre mondiale provenant de Mgr Gabriel de Llobet. L'évêque de Gap avait alors été mobilisé comme aumônier, alors qu'il venait d'accéder à l'épiscopat, et en avait relaté l'expérience. À partir d'un ensemble de sources archivistiques variées, essentiellement ecclésiastiques, il donne désormais une biographie de l'archevêque d'Avignon, qui consonne avec l'attachante notice que Jacques Prévotat avait consacrée à Mgr de Llobet

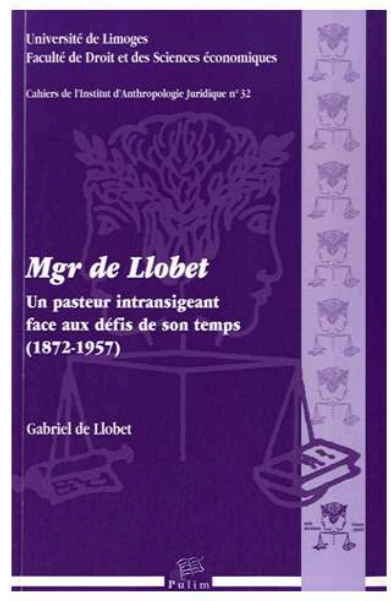
dans le Dictionnaire des évêques de France (Paris, Le Cerf, 2010, p. 422-423).

Le travail est de facture fort classique, dans son déroulé et dans sa méthode, qui n'est pas sans rappeler ces biographies que produisit l'érudition ecclésiastique et universitaire tout au long des $\mathrm{XIX}^{\mathrm{e}}$ et $\mathrm{xx}^{\mathrm{e}}$ siècles. Il fait une large place aux citations des documents utilisés : souvenirs et mémoires, pièces administratives, correspondance. Il prend l'archevêque à sa naissance (1872) et le situe dans son milieu familial, replacé dans son contexte local et socio-économique. Il le suit dans son éducation, sa formation ecclésiastique, puis sa carrière: ordination en 1896, secrétaire de l'évêque de Montpellier, Mgr de Cabrières, en 1897, curé puis vicaire général de Perpignan, en 1907, évêque de Gap en 1915, coadjuteur avec droit de succession de l'archevêque d'Avignon en 1925, archevêque d'Avignon en 1928, avec un coadjuteur à partir de 1955, décès et obsèques en 1957. Il s'attarde sur les points plus saillants : la Première Guerre mondiale et son ombre portée (mission officielle en Orient au nom de la France en 1919-1920), la condamnation de l'Action française, le rapport à Vichy. Il donne enfin à voir l'activité pastorale de l'évêque et de l'archevêque, du point de vue de la prise de décision et de l'orientation de l'action, et n'oublie pas le portrait humain et spirituel, que la correspondance et les notes de Mgr de Llobet permettent d'approcher d'assez près.

3 Une ligne directrice structure ce parcours biographique : comment la fidélité voulue aux traditions reçues permet-elle de s'insérer dans des temps fondamentalement changeants? Cette interrogation commande le travail, en partie parce qu'elle s'impose d'elle-même. En effet, Mgr de Llobet participe d'un milieu qui a fait de la fidélité indéfectible à ce qui fut le paradigme de son existence. De plus, il a lui-même voulu faire de cette conformité à ce qu'il avait reçu l'élément structurant de sa vie, choisissant d'être ce que ses racines l'avaient fait. Aristocrate légitimiste et catholique intransigeant, ces deux réalités furent pour lui matricielles. Or, comme tous ceux qui se réclamaient de ces éléments, il dut faire face aux transformations de ces réalités selon leur logique interne et leurs interactions entre elles et avec le reste de la société. L'affirmation de l'Action française dans la République anticléricale puis victorieuse ; le choix romain de la défense religieuse puis de l'entente avec la République et de l'Action catholique ; ce furent les données qu'il eut à assumer. Comme évêque, il s'en tira bien, globalement. S'il fut le dernier évêque français à manifester sa soumission à la condamnation de l'Action française en 1927, pour des raisons qui ne relèvent pas du maurrassisme mais assez largement des modalités d'exercice de l'autorité papale dans 
l'affaire et de la difficulté des évêques à comprendre clairement ce qui était attendu d'eux, il fut aussi un évêque qui n'ignora pas l'Action catholique, y compris dans ses transformations d'après 1945, et sut s'appuyer sur son clergé et ses collaborateurs pour la développer de manière structurelle. S'il conserva viscéral son royalisme, il sut entretenir des relations paisibles avec la Troisième République, cordiales avec Vichy, aimables avec la IV République.

4 À partir des éléments apportés par G. de Llobet, quelques points plus particuliers peuvent retenir l'attention. Tout d'abord, la carrière de Mgr de Llobet doit beaucoup à son enracinement familial et religieux. Ses racines familiales le mettent en relation avec Mgr de Cabrières, ce qui lui permet d'être, dès après son ordination, initié aux responsabilités administratives diocésaines, échappant ainsi à son diocèse d'ordination (Perpignan) et tissant des relations utiles. Ainsi peut-il être promu rapidement curéarchiprêtre à Perpignan, malgré une certaine opposition locale, puis vicaire général de son diocèse. Son expérience héraultaise lui donne alors une force non négligeable. Sa promotion à l'épiscopat s'appuie quant à elle non seulement sur ce passé d'administrateur, mais aussi sur l'inscription au sein des réseaux intransigeantistes. Formation au Séminaire français de Rome, adhésion à la défense religieuse, Gabriel de Llobet a tout ce qu'il faut pour correspondre au profil de l'évêque majoritairement choisi depuis les années 1906-1910. Relevons au passage que le choix du Séminaire français de Rome, au terme des études secondaires, relève bien de ces vocations d'élites sociales décidées au début de l'âge adulte en partie par le biais de retraites d'élection : le sacerdoce est aussi une profession choisie. Enfin, le transfert de Gap à Avignon s'inscrit dans l'apogée de la poussée intransigeantiste dans les nominations épiscopales, juste avant que la condamnation de l'Action française ne bouscule profondément les critères de choix.

5 En ce qui concerne le portrait du prêtre, puis de l'évêque, G. de Llobet apporte des éléments fort intéressants. Je relèverai ici la pratique de l'ascèse de l'archevêque. En deux temps, il abandonne sa fortune à son évêché, en échange d'une rente annuelle. Loin de tout décorum, il mène une vie austère, dans une chambre simple contrastant avec le luxe relatif des pièces de réception de l'archevêché, s'abstenant de chauffage, faisant raccommoder ses vêtements. Cette ascèse personnelle s'accompagne de celle qui est directement suscitée par le ministère épiscopal, notamment les tournées de confirmation. La vie personnelle et spirituelle des évêques est encore difficilement intégrée par les universitaires, sauf exceptions. Elle manque encore d'un traitement dédié et visant à produire une signification historique. On ne peut que donc se réjouir de ces ouvertures et souhaiter un élargissement, à l'image de ce qu'avait ébauché le père Dominique-Marie Dauzet dans sa contribution au colloque consacré au Dictionnaire des évêques de France, et récemment publié (Frédéric Le Moigne, Christian Sorrel (dir.), Les évêques français de la Séparation au pontificat de Jean-Paul II, Paris, Le Cerf, « Histoire ", 2012, p. 173-184). 